\title{
Top Three Risk Factors of Coronary Artery Disease in Chittagong, Bangladesh
}

Abu Tarek |qbal ${ }^{*}$

M Jalal Uddin ${ }^{2}$

Shaikh Md Hasan Mamun'

Rajat Sankar Roy Biswas?

'Department of Medicine

Chattagram Maa-O-Shishu Hospital Medical College

Chittagong, Bangladesh.

${ }^{2}$ Department of Community Medicine Chattagram Maa-O-Shishu Hospital Medical College Chittagong, Bangladesh.

\section{*Correspondence to:}

\section{Dr. Abu Tarek lqbal}

Associate Professor of Medicine and Cardiology Chattagram Maa-O-Shishu Hospital Medical College Chittagong, Bangladesh.

Mobile : +8801711107987

Email:dr.tarekiqbal@yahoo.com

\begin{abstract}
Background: Many studies were conducted on the subject in home and abroad but there is none in Chittagong, Bangladesh. To know about top three risk factors for coronary artery disease we conducted the study. Methods: It was a retrospective study. Records of a private cardiac center from July 2013 to June 2014 was collected. Only coronary stenosed cases (As per angiogram) was studied. Age, sex, BMI, diabetes mellitus, hypertension, smoking and other risk factors were considered. Collected data was managed manually. Finally discussion was made and conclusion was done. Results: Majority cases 58(76\%) were of 40-60 years age group. Male preponderance was there $64(83 \%)$. BMI of $45(60 \%)$ cases was normal $(<25)$. Family history was positive among $11(14 \%)$ cases. Dyslipidemia was found in $08(10 \%)$ cases, $56(73 \%)$ cases were hypertensive, $43(56 \%)$ cases were type-2 diabetic and 35(45\%) were smoker. Conclusion: Hypertension, Diabetes and Smoking are top 03 risk factors for coronary artery disease. All are modifiable. So, primordial prevention should be taken to reduce prevalence of coronary artery disease.
\end{abstract}

Key words: Risk factors; Coronary artery disease; Dyslipidemia.

\section{INTRODUCTION}

Coronary artery disease (Synonym: Coronary heart disease, Ischaemic heart disease) has been defined as "Impairment of heart function due to inadequate blood flow to the heart compared to its need caused by obstructive changes in coronary circulation $^{1}$. It claims $30 \%$ deaths in developed countries and WHO describes it as modern epidemic throughout the world. The disease may manifest in following ways:

- Angina pectoris

- Myocardial infarction

- Arrhythmia

- Cardiac failure

- Sudden death

Natural history of disease varies widely. Some may die in first attack and some after long history of disease ${ }^{2}$.

The disease is caused by multiple risk factors. The more the risk factors the more chance of occurrence of disease. The principal risk factors are: 


\author{
A. Modifiable Risk Factors \\ - Smoking \\ - Hypertension \\ - Dyslipidemia \\ - Diabetes mellitus \\ - Obesity \\ - Sedentary habits \\ - Stress \\ B. Non-modifiable Risk Factors \\ - Age \\ - Sex \\ - Positive family history
}

Main objective of the study is to make a ranking of risk factors of coronary artery disease in Chittagong so that we can identify top notorious factors. As a result we could reduce coronary artery disease significantly.

\section{MATERIALS AND METHODS}

It was a retrospective study. All positive coronary angiographic reports were collected from a private cardiac center of Chittagong. Study period was 01 year (July 2013-June 2014). Sample size was conveniently fixed. It was 77. All reports were meticulously studied. Data was manually managed and presented with tables. Results were contrasted with other studies of home and abroad.

\section{RESULTS}

Total 77 cases were studied. Angiographic reports of all cases manifested various stenosis. Among the cases 05(06\%) cases were below 40 years. $58(76 \%)$ cases were of $40-60$ years age group and remaining $14(18 \%)$ were above 60 years age group. Male were $64(83 \%)$ and $13(17 \%)$ were female. BMI of $45(58 \%)$ cases was normal $(<25), 24(31 \%)$ were over weight and $08(11 \%)$ were obese. Modifiable risk factors were: Hypertension 56(73\%), Diabetes 43(56\%), Smoking 35(45\%) and Dyslipidemia 08(10\%). Positive family history was $11(14 \%)$ only.

Table 1 : Age structure of coronary artery disease cases.

\section{Age structure}

\section{No. of cases $(\%)$}

$\begin{array}{lr}<40 \text { years } & 05(06 \%) \\ 40-60 \text { years } & 58(76 \%) \\ >60 \text { years } & 14(18 \%) \\ \text { Total } & \mathbf{7 7 ( 1 0 0 \% )}\end{array}$

Source: CMPH 2014

Table 2 : Sex structure of coronary artery disease cases.

\begin{tabular}{lc} 
Sex of patients & No. of cases $(\%)$ \\
Male & $64(83 \%)$ \\
Female & $13(17 \%)$ \\
Total & $\mathbf{7 7 ( 1 0 0 \% )}$ \\
\hline
\end{tabular}

Source: CMPH 2014
Table 3 : BMI of coronary artery disease cases.

$\begin{array}{lr}\text { BMI of cases } & \text { No. of cases }(\%) \\ <25 \text { (Normal) } & 45(59 \%) \\ 25-30 \text { (Overweight) } & 24(31 \%) \\ >30 \text { (Obese) } & 08(10 \%) \\ \text { Total } & \mathbf{7 7 ( 1 0 0 \% )}\end{array}$

Source: CMPH 2014

Table 4 : Risk factors of coronary artery disease cases.

\begin{tabular}{lc} 
Risk factors & No. of cases (\%) \\
Hypertension & $56(73 \%)$ \\
Diabetes Mellitus & $43(56 \%)$ \\
Smoking & $35(45 \%)$ \\
Positive family history & $11(14 \%)$ \\
Dyslipidemia & $08(10 \%)$ \\
\hline
\end{tabular}

Source: CMPH 2014

\section{DISCUSSION}

According to present study most risky age group for coronary artery disease is $40-60$ years covering $58(76 \%)$ cases. In America $37 \%$ male and $29 \%$ female die due to myocardial infarction below 55 years age group. This is consistent with $76 \%$ stenosis (CAD) of present study because myocardial infarction is definitive for coronary artery stenosis ${ }^{3}$.

Present study shows male $83 \%$ and female $17 \%$ suffered from coronary artery disease. It is about $5: 1$. Previous report shows $4: 1$ but over 70 years the ratio was almost equal ${ }^{3}$.

BMI is unrelated to coronary artery disease $\mathrm{A}^{4}$. According to present study only $08(10 \%)$ cases were obese (BMI $>30)$.

According to NICVD (1997) 14\% of MI cases had positive family history ${ }^{3}$. Present study also shows $14 \%$. Information about sedentary life style is skipped here because it was not recorded in primary data sheet. Dyslipidemia was found only $08(10 \%)$ cases of coronary artery disease cases.

Present study shows top 03 risk factors are Hypertension 56(73\%), Type -2 Diabetes 43(56\%) and Smoking 35(45\%). Hypertension is the single most notorious risk factors for coronary artery disease because it accelerates atherosclerotic changes in blood vessels ${ }^{2}$. It ranks first position in our study. Next notorious factor is Diabetes which contributes 30-50\% deaths among coronary artery disease cases. It ranks $2^{\text {nd }}$ position in our study ${ }^{5}$. According to NICVD Smoking was found among $43 \%$ cases and our study shows $45 \%$. No significant difference has been detected among the figures of different studies $(\mathrm{p}<0.05)$. 


\section{CONCLUSION}

Hypertension, Type-2 diabetes and Smoking are 3 most notorious risk factors. Combination of these factors increases IHD occurrence many folds. All are modifiable risk factors. So, appropriate measures (Primordial prevention) should be taken to reduce coronary artery diseases significantly.

\section{DISCLOSURE}

All the authors declared no competing interest.

\section{REFERENCES}

1. WHO. Technical report series. No. 678. 1982.

2. Park. Text book of Preventive \& Social medicine. Jabalpur(India): Banarashi Das Bhanot: 2005.

3. Probir. Healthy Heart. Chittagong: Chittaranjon Das: 1999.

4. BMI \& CAD. Available at http://sevencountriesstudy.com/body-fatness-and-coronary-heart-disease.

5. WHO. Technical report series. No. 727. 1985. 